\title{
The sustainability aligned mandate on retail infrastructure: with respect to redesign, retrofit, rejuvenation
}

\author{
Salil K Sen \\ Visiting Professor \\ Sustainability Management School, Geneve, Switzerland and \\ Institut-Mines Telecon, Evry, France and \\ NIDA Business School, National Institute of Development Administration, Bangkok, Thailand \\ Viput Ongsakul \\ NIDA Business School \\ National Institute of Development Administration (NIDA), Bangkok, Thailand
}

\begin{abstract}
Keywords
Sustainability of retail infrastructure; resilience from ageing; sustainable use of resources in retail and responsible consumption; enhancing implementation of the Sustainable Development Goals; retail Infrastructure rating tool; adaptability of sustainability aligned retail infrastructure across ASEAN, SAARC, Middle east and North Africa with European Union, North America and Latin America
\end{abstract}

\begin{abstract}
This paper charts the sustainability aligned mandate on retail infrastructure roadmap with respect to (i) resilience to vulnerability of ageing retail infrastructure (ii) value-bridge between business of retail growth with responsible consumption to enhance implementation of the Sustainable Development Goals. (iii) possibility of Sustainability aligned- retail Infrastructure rating tool (iv) adaptability of Retail Infrastructure across ASEAN, SAARC, Middle east and North Africa along with research notes on future best practices in European Union, North America and Latin America. The overall fabric of special issue of the Journal of Business \& Retail Management Research (JBRMR) themed on Impact of Sustainable Development Goals on Retail Infrastructure received an array of innovative, substantive and robust submissions. Modelling and coordination mechanisms with respect to retail infrastructure competitiveness with sustainability addressed the alliance coordination mechanisms on Retail Infrastructure from the governance lens (Ongsakul, Parameswar and Dhir, 2019). The next paper on the Promoting Responsible Service Policy attributes perceived service recovery performance on retail infrastructure sustainability (Nuansi $\mathcal{E}$ Ngamcharoenmongkol, 2019). The complaints and issues resolution play a significant role in ensuring reputability of retail infrastructure. This opens innovative avenues for retail research frontiers with respect to redesign, retrofit, rejuvenation in facets of Retail Infrastructure. Sustainable development in practice with a reality check-based case analysis on a reputable retail leader underscores the dynamic recast, reconstruct and revitalization needs for retaining leadership position in retail infrastructure (Withisuphakorn, Batra, Parameshwar and Dhir, 2019). While the Retail Infrastructure Alliance model underscore the role of services, two papers in this special issue build Retail services as a value bridge, namely, the paper on the influence of Sustainable Development Goals (SDGs) on Customer-Based Store Equity (Soonsiripanichkul and Ngamcharoenmongkol, 2019) and brand personality's role to achieve the Sustainable Development Goals (SDGs) for Small and Medium-Sized Enterprises (SMEs) in Thailand (Auemsuvarn, 2019).
\end{abstract}

First Guest Editor: Salil K Sen

Email addresses for the first Guest Editor: salil.sen@gmail.com

Second Guest Editor: Viput Ongsakul

Email address for the second Guest Editor: vongsakul@nida.ac.th

Introduction

Business and retail management research is in the introspection mode, deliberating how it's span, reach and domain could get currency and further rigor. This special issue on the impact of the Sustainable Development Goals on Retail Infrastructure provides the needed momentum to interface with 
sustainability on retail. Added impetus propel authors with characteristic perspectives with respect to the adaptability of retail infrastructure across ASEAN, SAARC, Middle east and North Africa with European Union, North America and Latin America. Indeed, a worthy task for the Journal of Business and Retail Management Research (JBRMR). This paper emphasizes that retail needs to embed responsibility management, to add beyond the economic value of retail business. This research takes into cognizance the imperativeness of bringing into the retail research conversation the implementability of the Sustainable Development Goals (SDGs). This special issue introduction paper is tasked to address the sustainability aligned mandate on retail infrastructure, with respect to redesign, retrofit, rejuvenation.

Sustainability-aligned retail infrastructure presents actionable disaster-resilient and SDG-compliant innovations for implementation in the ambiance of vulnerability. The vulnerability of ageing retail infrastructure could potentially be a trillion-dollar liability that could be managed with a top-downbottom-up alignment of infrastructural financing needs. This special issue offers a value-bridge between disaster resilience and implementation of the SDGs in a multidisciplinary trajectory. Science driven by policy governance ushers in innovation. Proper and sustained implementation is a function of metrics and indicators and umbrella-testing of the targets ((Mitchell et. al. 2013; Simon, 2015). Retail infrastructure rating tools need to encompass resiliency with respect to disasters as well as the sustainability with respect to economic, societal and environmental indices that conform with the broader domain of business of retail (Diaz Sarachaga et. al. 2016). Sustainability-linked retail infrastructure nurtures innovation. This has the potential to be transformative for retail business.

The special issue has a bouquet of contributions that present innovation, entrepreneurship, corporate social responsibility, climate proof financing and disaster-proofing retail infrastructure. This issue intends to encourage conversation concerning the renewal of the role of retail managers, retaillinked entrepreneurs and retail-driven innovators to recast sustainability practice with the core intent of SDG-compliant retail infrastructure. A plethora of emerging issues related to retail infrastructure, sustainability conjunction, are, (i) disruptive interventions, (ii) possibility of adoption of Internet of Things in retail infrastructure, (iii) disaster resilience for retail infrastructure, (iv) societal entrepreneurship for down-stream and upstream stakeholders of retail infrastructure (v) results-based financial investments to redesign, retrofit and rejuvenate ageing retail infrastructure.

This introductory research initiates into the multi-pronged initiatives such as (a) mainstreaming technology coupled with social engineering, (b) vigilant monitoring and self-corrective response for timely coping with hazard events, (c) adapting technologies to strengthen infrastructure for retail infrastructure (Kaoru, 2016). Disaster-resilient and SDG-compliant retail infrastructure has benefits that include (i) low-carbon indigenously adapted stand-alone energy-water-waste integrated habitats, (ii) entrepreneurial opportunities that sparks innovation, and (iii) climate-proof financing by private-sector entrepreneurs.

The combined sustainability - retail development trajectory needs redesign, retrofit and rejuvenation. The utilities footprint of retail infrastructure is not limited to the confines of the built environment but extends as a retail-infrastructure eco-system. The utility systems need to be selfreplenishable through endurability drawn from sustainable processes. This research paper probes the symbiotic common-ground for sustainability for the retail - infrastructure combine. The intrinsic motivation to embed sustainability practice onto retail infrastructure would be to co-implement quantum innovations and adaptations. The spirit of value-creation needs governance mechanisms to usher pathways on symbiosis for sustainability. Intended outcomes are (a) budgeting social reputation, (b) symbiotic scale-up that would attain efficiency and ease of implementation. An important destination is trust renaissance between retailers and the consumers and potential consumers. This paper addresses the common-ground challenges facing retail infrastructure. The paper posits a dual aimed methodology (i) where retailers and consumers need to be in the search-mode for symbiotic common-ground for sustainability embedded retail experience and (ii) the trajectory that upstream and down-stream vendors likely to follow that mainstreams the adoption of sustainable development goals along with the achievement of economic market share targets. The unified motivation would be to co-implement quantum innovations and adaptations on governance mechanisms to usher pathways on symbiosis for sustainability.

www.jbrmr.com A Journal of the Academy of Business and Retail Management (ABRM) 


\section{The retail sustainability infrastructure rationale}

The concept of carrying capacity limit for resources that support the retail infrastructure is dealt here. The desired characteristics are (a) self-replenishable resources, such as water-consumed, wastegenerated and energy utilized in retail infrastructure (b) endurability drawn from prospective ecoprocesses (Dakhia \& Berezowska-Azzag, 2010). When redesign-ability is juxtaposed with water - waste energy retrofit-ability, sustainable value is created. The two together serves as a determiner of continuous environmental performance (Lyakurwa, 2014). Extreme-weather events, catastrophes and natural disasters are quite frequent. The onset of such phenomenon necessitated paradigmatic shifts with respect to retail infrastructure. Ongoing evaluation on social change has significant effect too on retail performance. Retail infrastructure may be considered as co-habitation of technology \& nature (Tamari, 2014; Leonard, 2007; Martinez-Alier, 2007). Analogically, sustainability serves as the entropy for envirosocio-economic sustenance of retail infrastructure. These provide the research gap in processes, transitions and infrastructure services in the retail infrastructure arena (Pauliuk \& Hertwich, 2015). Social metabolism is the quantum of societal material and energy for robust continuity (Ayres \& Kneese, 1969). Extrapolating environmental measures to span retailers - vendors - service providers, create the social fabric to enable direct and indirect energy and emissions reduction in key sectors allied to retail infrastructure, namely, transportation, buildings, and industry (Kovacic, \& Giampietro, 2017). Budgeting water, waste, energy from retail infrastructure can decouple energy dependence and moderate lifestyle (Pauliuk \& Müller, 2014). The sustainability need is challenging their respective agrarian and urban demand for resources (Ayres \& Simonis, 1994).

The common ground for sustainability adoption depends on technology-adapted, entrepreneurial innovation-driven and proactive behavioural change approaches (Dentchev, Rauter, Jóhannsdóttir, Snihur, Rosano, Baumgartner, R., ... \& Jonker, 2018). Evidences indicate renewable options from renewable energy in retail infrastructure is reaching utility-scale (Lewis, 2007). It is without question that shared value-based developmental outcomes outweigh any intricacies between economic pursuit and societal - environmental aspirations. Competence in indigenous innovation, skilled manpower are key determinants of implementation of the sustainable development goals in the domain of retail infrastructure. Increasingly retail infrastructure is impacted by climate change, and disaster vulnerability (Renner, 2007). The competing retailers are worthy to of symbiotic paradigms given the value creation in the sustainable term with finite sharing of natural resources (Yanarella \& Levine, 2011). Growing security concerns also eat-up valuable resources for retail infrastructure. Instead, shared value-based sustainable development on the symbiotic architecture would be a win-win for retail infrastructure and peripheral stakeholders (Zhang, Wu, Wang, Fath, Liu, Hao \& Li, 2017; Ramaswamy \& Gouillart, 2010). Scale-up at retail store level compared to symbiotic scale-up at the retail infrastructure resource-blockchain level would usher sustainability, along with efficiency and practicality (Yanarella, 2018). Retail infrastructure may be considered as a sub-set of smart cities initiatives. Multiple commonality fosters willingness to work in consensus (Reed, Van Vianen, Deakin, Barlow \& Sunderland, 2016). The visionary leadership of the retail infrastructure conglomerates could provide the momentum for industriousness (Cabrera \& Unruh, 2012). Strategic trust could germinate on confidence building initiatives on ecology, economy and empathy based symbiotic sensitivity (Flint, 2012). Based on this rationale the paper embarks on literature review based on the exigency of: (a) redesign (b) retrofit (c) rejuvenate retail infrastructure. Interestingly, the sustainability-aligned retail infrastructure could be a determiner of the circular economy concept.

\section{Literature review}

Resilience to vulnerability of ageing retail infrastructure:

This introductory article to the special issue derives literature support on trust renaissance, that brings together the motivation to assess the symbiotic common ground for sustainability (Diekhöner, 2017). Trust at the consumer-level emanates from self-regulation and leads to reinterpretation of the inherent benefits of sustainability-embedded retail infrastructure (Schepel, 2005). Given the potential of water conservation, waste curb and energy savings, retail infrastructure derives from good governance architecture is to be deployed with wisdom (Mathur, Zhang \& Neelankavil, 2001). Retail infrastructure resolves and pre-empts issues on partnered energy sector related greenhouse gas emission reduction (Kroeze, Vlasblom, Gupta, Boudri \& Blok, 2004) and contentions (Emmott, 2009; Srinivasan, 2006). 
Sustained benefits from resource optimization accrue from beyond-compliance policy interventions (Cohen-Rosenthal \& Musnikow, 2017; Singh, Padmanabhan \& Emanuel, Eds., 2017; Emmott, 2009; Vandenbergh, 2017). Retail marketing spend often ignore sustainability issues. In order to integrate this aspect, literature specifies the phenomenon to curb super diversity (Vertovec, 2007). The gender aspects of larger-than-life positioning in retail infrastructure hoardings, billboards, and long-hours of intense glowsigns, are specific areas that need attention of retail infrastructure redesigners, retrofitters and rejuvenators. The resource inequity issue needs balancing the social and environmental capital accrual in the process of retail infrastructure development. Gender issues with respect to consumers have pertinent impact for creating sustainability-pull in contrast to the market-reliant push for the expansion of retail (Sen, 1997). The vast online markets can serve as the basic enabler to promote symbiosis for sustainability (Nolan, 2005). Entrepreneurial ecosystems evolve as connective networks to bridge the boundary-zone differences (Neumeyer, Santos, Caetano \& Kalbfleisch, 2018). Customer relations need to assume priority. They should share positivity on the international landscape issues (Zhao, 2007). This posits the issue of value bridge between partnerships between responsibility and retail infrastructure, as elaborated in the next section.

(ii) value-bridge between business of retail growth with responsible consumption to enhance implementation of the Sustainable Development Goals. Healthy habitat reverses emissions through the self-sufficiency and proximity principle with community guarantee for the maximal safeguard of environment and health (Mamì \& Mormino, 2014). Restructuring retail infrastructure with sense of proactive concern for water, waste energy can be configured both in urban and rural settings (UN-Habitat, 2016). It is customary to observe the foregrounding of the city as the epicenter of investment driving development (Hutton, 2004).

\section{(iii) possibility of Sustainability aligned- retail Infrastructure rating tool}

The literature has support for the search of sustainability aligned retail infrastructure. Though, rural retail infrastructure prospects as they tend to be relegated (Fan, 2003). This aspect serves as an opportunity, as retail produce could be sourced economically. This would in-turn curb provincial inequity interspersed with poverty-traps (Jalan \& Ravallion, 2002). Certain pockets receive urban investment support are better placed than rural centers. This results in detrimental effects with respect to poverty (Onyebueke and Hope, 2011). Sustainability-aligned retail infrastructure has the elemental ability to cogrow (Gandy, 2004). This could spur public-private-community financing in the entrepreneurial mode through bio-bank governance (Gottweis \& Lauss, 2012). This societally benign and environmentally beneficial developmental strategy for retail could convince financiers, urban planners and investors both from urban and rural retail formats. A direct benefit that would accrue on local sourcing (Li \& Wei, 2011) that has fall-outs on assimilation for culture and adaptation for locale specific conditions (Nee \& Alba, 2012). The issue of transformation through retrofit is evocative creator of opportunity for sustained shared-value creation (Autio \& Thomas, 2014). The contentious issue here is that consideration for the environmental well-being deserves prime attention. Often, the over-crowded, unhygienic urban retail infrastructure could be remedied with appropriate redesign. An important outcome is likely reversal of retail-driven migration (Ford \& Hill, 1971). In the sustainable time-term, it makes sense to usher grassroots implementation of the sustainable development goals for retail infrastructure that creates sense of shared value (Burnley, 2016). The shared value can also manifest as green services in a public-private coupled domain (Morse, 2010). This can enhance eco-efficiency. The value of green services and technologies and innovative applications of green technologies provide good rationale for financing mainly on recycling and development of brownfield regeneration (Piacentini, 2012).

\section{Methodology for attaining redesign, retrofit, rejuvenation}

Redesign, retrofit and rejuvenation of retail infrastructure

Geographically open cascades in retail infrastructure identifies redesign-ability segments across related entities thereby sharing resource consumption (Geng, Sarkis, Ulgiati \& Zhang, 2013). The methodology adopted for this conceptual analysis is developing three steady state archetypes (described below), that are based on local aggregation with externalities with respect to retail infrastructure (Bocken, Short, Rana \& Evans, 2014). As a cross-check to the viability of the methodology, issues such as, 
optimizing water, waste, energy for sustainability is assessed with literature support. The goal is to attain the right kind of metric that would assess (i) how much self-replenishable the retail infrastructure is (ii) would sustain the carrying capacity in terms of footfalls in retail infrastructure. This section focuses on the qualitative methodology to attain the above. The literature review serves the following steady state archetypes for determinative action with respect to sustainability-aligned retail infrastructure:

Emphasis on redesign: continuous sustainability pursuit through harnessing water along with energy and waste Focus on retrofit common ground for future-proofing eco-efficiency, rural - urban or rurban equity

Pre-eminence on rejuvenation: assimilation of the sustainability attained through shared approach on water - waste - energy inter-dependence

(a) Emphasis on redesign: Assessing potential pathways for continuous sustainability pursuit through harnessing water along with energy and waste

The management of waste is a key prerogative for retail infrastructure. Such pursuits could drive newer avenues of innovation both up-stream and down-stream retail infrastructure stakeholders. Retraining, re-skilling and recruitment create opportunities for re-deployment for displaced or redundant retail skill-force. The eco-industrial development may happen as a supplementary benefit with robust retail infrastructure financing (Sertyesilisik \& Sertyesilisik, 2016). Financiers would also be interested in investing in education and training relevant to the transition towards greener production and waste recycling modes. This situation would significantly enhance the financing appetite for investors who address retail infrastructure sustainability-opportunity holistically. The vast and quality aspiring consumer bases benefit from shared value arising from the rising demand for low-carbon services. This would consolidate the domain and widen the reach by comprehensively covering a spectrum of sectors (Hassan, Nazem \& Islam 2016). There is growing evidence of results-based financiers and insurers investing across ASEAN, SAARC, Middle east and North Africa with European Union, North America and Latin America, rather than in individual countries. This also ensures better risk spread (Nanto, 2011; Gray \& Moody-Stuart, 2006). Literature indicates that destination of foreign direct investment is correlated to high levels of gross domestic product, high domestic savings, large foreign reserves and export orientation (Bano \& Tabbada, 2015). Quantum of inflows may vary with the level of development. Given the sheer developmental potential of retail infrastructure, a transform from inwardly directed to shared value-orientation, will alter the investment effectiveness. This assessment would serve as a significant methodological step needed for redesign, retrofit and rejuvenation linking policy makers, private financiers, processors and peoples in the sustainable retail infrastructure domain.

(b) Focus on retrofit: Gauging the common ground for futureproofing for eco-efficiency:

Measures to address the metabolic shortfall with respect to sustainability would make the pitch for the retail infrastructure common ground search. Rapid growth leveraged by economic development has precipitated severe issues with respect to disaster vulnerability, carbon-effusion and waste proliferation (Dakhia \& Berezowska-Azzag, 2010). It is well endorsed that sustainability-aligned retail infrastructure is at the crossroad of spectacular transformation, due to rapid urbanization. To fuel export as well as spur domestic goods appetite, emphasis tilted to industry, process innovation, supply chain and productivity. The environmentally and societally unwelcome fallout is the economic emphasis.

(c) Pre-eminence on rejuvenation: Metabolism assists assimilation of the sustainability attained through symbiosis of shared approach on water - waste - energy inter-dependence to re-invigorate smart urban with robust rural

The rejuvenation archetype blends with smart ecology-aligned cities. This needs enormous quantities of water and energy and would generate colossal waste. According to International Energy Agency, retail account for significant quantum of energy worldwide. This fact has implications on water energy availability and the simultaneous treatment of waste. Rejuvenation enhances the carrying capacity and improves the self-replenishment ability. It assists the process of assimilation of water - waste - energy shared value. This is expected to enhance the shared bargain-ability of the two joint entities in energy water - waste negotiations. Rejuvenation fits into low-carbon and circular economy. Low-carbon and circular economy is pivoted on waste management. To maintain the consistent economic growth balanced 
with environmental and societal value added, the resources of energy and water need to be enhanced. This is possible with waste utilization, as both water free of contamination or waste and energy devoid of carbon, also considered as waste, need proper alignment. There is strong interdependence between water and energy as most of the energy production processes require a significant amount of water and the treatment and transfer of water requires energy usually in the form electricity. The energy production technologies adopted determines the amount of water required to produce a given quantum of energy. Similarly, the availability and allocation of fresh water resources determine the amount of water that can be used for energy production. Waste is a common determiner of clean water and clean energy.

\section{Discussion, future pathway}

Enhancing factors that emerge are water - waste - energy. Non-agricultural water - energy demand and proliferation of non-agricultural waste, create stress on societal equity (Cai, 2008).

Retail infrastructure when blended with eco-urban innovations (Yanarella, 2018) can germinate sustainability intent. Low carbon circular economy is the future pathway. This important outcome of this research is designing resilience with respect to retail infrastructure (Jones, Pimbert \& Jiggins, 2010). With this introduction paper to the mandate on sustainability-aligned retail infrastructure, following contributions enrich the conversation:

Competitiveness: Modelling and coordination mechanisms with respect to retail infrastructure competitiveness with sustainability addressed the alliance coordination mechanisms on Retail Infrastructure from the governance lens (Ongsakul, Parameswar and Dhir, 2019).

Service Responsibility in retail infrastructure: The next paper on the Promoting Responsible Service Policy attributes perceived service recovery performance on retail infrastructure sustainability (Nuansi \& Ngamcharoenmongkol, 2019). The complaints and issues resolution play a significant role in ensuring reputability of retail infrastructure. This opens innovative avenues for retail research frontiers with respect to redesign, retrofit, rejuvenation in facets of Retail Infrastructure. Revitalization needs: Sustainable development in practice with a reality check-based case analysis on a reputable retail leader underscores the dynamic recast, reconstruct and revitalization needs for retaining leadership position in retail infrastructure (Withisuphakorn, Batra, Parameshwar and Dhir, 2019). While the Retail Infrastructure Alliance model underscore the role of services, two papers in this special issue build Retail services as a value bridge.

SDGs \& store equity: namely, the paper on the influence of Sustainable Development Goals (SDGs) on Customer-Based Store Equity (Soonsiripanichkul and Ngamcharoenmongkol, 2019).

SDGs and brand personality: brand personality's role to achieve the Sustainable Development Goals (SDGs) for Small and Medium-Sized Enterprises (SMEs) in Thailand (Auemsuvarn, 2019).

\section{References}

Autio, E., \& Thomas, L. (2014). Innovation ecosystems. The Oxford handbook of innovation management, 204288.

Ayres, R. U., \& Kneese, A. V. (1969). Production, consumption, and externalities. The American Economic Review, 59(3), 282-297.

Ayres, R. U., \& Simonis, U. E. (1994). Industrial metabolism: Restructuring for sustainable development.

Bocken, N. M., Short, S. W., Rana, P., \& Evans, S. (2014). A literature and practice review to develop sustainable business model archetypes. Journal of cleaner production, 65, 42-56.

Cabrera, A., \& Unruh, G. (2012). Being global: How to think, act, and lead in a transformed world. Harvard Business Press.

Cai, X. (2008). Water stress, water transfer and social equity in Northern China-Implications for policy reforms. Journal of Environmental Management, 87(1), 14-25.

Castles, S., De Haas, H., \& Miller, M. J. (2013). The age of migration: International population movements in the modern world. Palgrave Macmillan.

Cohen-Rosenthal, E., \& Musnikow, J. (2017). The role of government in eco-industrial development. In Eco-industrial Strategies (pp. 68-88). Routledge. 
Dentchev, N., Rauter, R., Jóhannsdóttir, L., Snihur, Y., Rosano, M., Baumgartner, R., ... \& Jonker, J. (2018). Embracing the variety of sustainable business models: A prolific field of research and a future research agenda. Journal of Cleaner Production.

Diekhöner, P. K. (2017). The Trust Economy: Building strong networks and realising exponential value in the digital age. Marshall Cavendish International Asia Pte Ltd.

Emmott, B. (2009). Rivals: How the power struggle between China, India and Japan will shape our next decade. Houghton Mifflin Harcourt.

Fan, C. C. (2003). Rural-urban migration and gender division of labor in transitional China. International Journal of Urban and Regional Research, 27(1), 24-47.

Flint, R. W. (2012). Practice of sustainable community development: a participatory framework for change. Springer Science \& Business Media.

Ford, W. F., \& Hill, L. E. (1971). Reverse Migration and Population Dispersion: A Partial Solution for Urban Problems. Nebraska Journal of Economics and Business, 45-60.

Gandy, M. (2004). Rethinking urban metabolism: water, space and the modern city. City, 8(3), 363-379.

Geng, Y., Sarkis, J., Ulgiati, S., \& Zhang, P. (2013). Measuring China's circular economy. Science, 339(6127), 1526-1527.

Gottweis, H., \& Lauss, G. (2012). Biobank governance: heterogeneous modes of ordering and democratization. Journal of community genetics, 3(2), 61-72.

Hutton, T. A. (2004). The new economy of the inner city. Cities, 21(2), 89-108.

Jalan, J., \& Ravallion, M. (2002). Geographic poverty traps? A micro model of consumption growth in rural China. Journal of applied econometrics, 17(4), 329-346.

Jones, A., Pimbert, M., \& Jiggins, J. (2010). Virtuous circles: values, systems and sustainability. International Institute for Environment and Development (IIED), London.

Leonard, A. (2007). Symbiosis and the viable system model, Kybernetes, Vol. 36 Issue: 5/6, pp.571-582,

Lewis, J. I. (2007). Technology acquisition and innovation in the developing world: Wind turbine development in China and India. Studies in comparative international development, 42(3-4), 208-232.

Li, Q., \& Wei, W. (2011). The Research Review of the Study on the Application of Symbiosis Theory in City Groups. Journal of Yulin University, 1, 016.

Kovacic, Z., \& Giampietro, M. (2017). Between theory and quantification: An integrated analysis of metabolic patterns of informal urban settlements. Energy Policy, 100, 377-386.

Kroeze, C., Vlasblom, J., Gupta, J., Boudri, C., \& Blok, K. (2004). The power sector in China and India: greenhouse gas emissions reduction potential and scenarios for 1990-2020. Energy Policy, 32(1), 5576.

Mamì, A., \& Mormino, L. (2014). Sustainable Urban Requalification: Circularity of Processes for a New Metabolism. Journal of Engineering and Architecture, 2(2), 2014.

Martinez-Alier, J. (2007). Social metabolism and environmental conflicts. Socialist register, 43(43).

Mathur, A., Zhang, Y., \& Neelankavil, J. P. (2001). Critical managerial motivational factors: A cross cultural analysis of four culturally divergent countries. International Journal of Cross-Cultural Management, 1(3), 251-267.

McDonough, W., \& Braungart, M. (2013). The upcycle: Beyond sustainability--designing for abundance. Macmillan.

Morse, R. S. (2010). Integrative public leadership: Catalyzing collaboration to create public value. The Leadership Quarterly, 21(2), 231-245.

Nee, V., \& Alba, R. (2012). Rethinking assimilation theory for a new era of immigration. In The new immigration (pp. 49-80). Routledge.

Neumeyer, X., Santos, S. C., Caetano, A., \& Kalbfleisch, P. (2018). Entrepreneurship ecosystems and women entrepreneurs: a social capital and network approach. Small Business Economics, 1-15.

Nolan, P. H. (2005). China at the Crossroads. Journal of Chinese Economic and Business Studies, 3(1), 1-22.

Onyebueke. V. and Hope, N. (2011) Rural-Urban 'Symbiosis', community self-help, and the new planning mandate: Evidence from Southeast Nigeria, Habitat international Volume: 35 Issue 2.

Pauliuk, S., \& Hertwich, E. G. (2015). Socioeconomic metabolism as paradigm for studying the biophysical basis of human societies. Ecological Economics, 119, 83-93. 
Pauliuk, S., \& Müller, D. B. (2014). The role of in-use stocks in the social metabolism and in climate change mitigation. Global Environmental Change, 24, 132-142.

Ramaswamy, V., \& Gouillart, F. J. (2010). The power of co-creation: Build it with them to boost growth, productivity, and profits. Simon and Schuster.

Reed, J., Van Vianen, J., Deakin, E. L., Barlow, J., \& Sunderland, T. (2016). Integrated landscape approaches to managing social and environmental issues in the tropics: learning from the past to guide the future. Global change biology, 22(7), 2540-2554.

Renner, M. (2007). Beyond disasters: creating opportunities for peace (Vol. 173). Worldwatch Institute.

Schepel, H. (2005). The constitution of private governance: Product standards in the regulation of integrating markets. Bloomsbury Publishing.

Sen, A. (1997). Development and Thinking at the Beginning of the 21st Century. IDEAS Working Paper Series from RePEc, 1997

Sigelman, L., \& Yanarella, E. J. (1986). Public information on public issues: A multivariate analysis. Social Science Quarterly, 67(2), 402.

Singh, H., Padmanabhan, A., \& Emanuel, E. J. (Eds.). (2017). India as a Pioneer of Innovation. Oxford University Press.

Srinivasan, T. N. (2006). China, India and the world economy. Economic and Political Weekly, 3716-3727.

Tamari, T. (2014). Metabolism: Utopian urbanism and the Japanese modern architecture movement. Theory, Culture \& Society, 31(7-8), 201-225.

UN-Habitat. (2016). Planning sustainable cities: global report on human settlements 2009. Routledge.

Vandenbergh, M. P. (2017). The Future of Environmental Enforcement.The Future of Environmental Enforcement.

Vertovec, S. (2007). Super-diversity and its implications. Ethnic and racial studies, 30(6), 1024-1054.

Yanarella, E. (2018). China's Urban Revolution: Understanding Chinese Eco-Cities. Sustainability: The Journal of Record, 11(1), 45-48.

Yanarella, E. J., \& Levine, R. S. (2011). The city as fulcrum of global sustainability. Anthem Press.

Yanarella, E. J. (1999). Local sustainability programmes in comparative perspective: Canada and the USA. Local Environment, 4(2), 209-223.

Zhang, Y., Wu, Q., Wang, X., Fath, B. D., Liu, G., Hao, Y., \& Li, Y. (2017). Analysis of the ecological relationships within the $\mathrm{CO} 2$ transfer network created by global trade and its changes from 2001 to 2010. Journal of Cleaner Production, 168, 1425-1435.

Zhao, H. (2007). India and China: rivals or partners in Southeast Asia? Contemporary Southeast Asia: A Journal of International and Strategic Affairs, 29(1), 121-142. 